\title{
Aging and the perception of slant from optical texture, motion parallax, and binocular disparity
}

\author{
J. Farley norman, Charles E. Crabtree, \\ Ashley N. Bartholomew, and Elizabeth L. Ferrell \\ Western Kentucky University, Bowling Green, Kentucky
}

\begin{abstract}
The ability of younger and older observers to perceive surface slant was investigated in four experiments. The surfaces possessed slants of $20^{\circ}, 35^{\circ}, 50^{\circ}$, and $65^{\circ}$, relative to the frontoparallel plane. The observers judged the slants using either a palm board (Experiments 1, 3, and 4) or magnitude estimation (Experiment 2). In Experiments 1-3, physically slanted surfaces were used (the surfaces possessed marble, granite, pebble, and circle textures), whereas computer-generated 3-D surfaces (defined by motion parallax and binocular disparity) were utilized in Experiment 4. The results showed that the younger and older observers' performance was essentially identical with regard to accuracy. The younger and older age groups, however, differed in terms of precision in Experiments 1 and 2: The judgments of the older observers were more variable across repeated trials. When taken as a whole, the results demonstrate that older observers (at least through the age of 83 years) can effectively extract information about slant in depth from optical patterns containing texture, motion parallax, or binocular disparity.
\end{abstract}

Over the past 200 years, researchers have thoroughly investigated the various sources of optical information that support the human perception of 3-D object shape. Any list of these sources would certainly include binocular disparity (e.g., Julesz, 1960, 1964, 1971; Wheatstone, 1838), motion parallax (e.g., Helmholtz, 1866/1925; Norman, Clayton, Shular, \& Thompson, 2004; Ono \& Wade, 2005; Rogers \& Graham, 1979, 1982), shading (e.g., Bülthoff \& Mallot, 1988; Todd, 1985; Todd \& Reichel, 1989), specular highlights (e.g., Norman, Todd, \& Phillips, 1995; Todd, Norman, Koenderink, \& Kappers, 1997), and gradients of optical texture (e.g., Andersen, Braunstein, \& Saidpour, 1998; Gibson, 1950a, 1950b; Newman, Whinham, \& MacRae, 1973; Rosas, Wichmann, \& Wagemans, 2004; Saunders, 2003; Todd \& Akerstrom, 1987; Todd, Thaler, \& Dijkstra, 2005). Although aging has been a subject of psychological interest for almost 100 years (e.g., Hall, 1922), little research on aging and the perception of 3-D object shape was conducted until about a decade ago.

In the past $10-15$ years, psychologists have begun to evaluate older observers' ability to perceive various aspects of 3-D object shape from binocular disparity (Norman, Crabtree, Herrmann, et al., 2006; Norman, Dawson, \& Butler, 2000), motion (Andersen \& Atchley, 1995; Norman et al., 2004; Norman, Dawson, \& Butler, 2000), shading (Norman, Crabtree, Norman, et al., 2006; Norman \& Wiesemann, 2007), and specular highlights (Norman, Crabtree, Norman, et al., 2006; Norman \& Wiesemann,
2007). All of these studies have shown significant negative effects of increasing age on the perception of 3-D shape. The age differences, however, have largely been quantitative; the qualitative patterns of older observers' perceptual judgments are typically similar to those exhibited by younger observers. Some of the largest age effects have involved the perception and discrimination of 3-D shape from motion (see, e.g., Norman et al., 2004; Norman, Dawson, \& Butler, 2000). This is perhaps not surprising, because other research has consistently shown that older observers' ability to detect and discriminate motion itself is reduced, relative to that of younger observers (see Habak \& Faubert, 2000; Norman, Ross, Hawkes, \& Long, 2003; Snowden \& Kavanagh, 2006). Likewise, 30 years of research have clearly demonstrated that older observers exhibit difficulty in detecting intermediate and high spatial frequencies (see, e.g., Arundale, 1978; Bennett, Sekuler, \& Ozin, 1999; Elliott, Whitaker, \& MacVeigh, 1990; Kline, Schieber, Abusamra, \& Coyne, 1983; McGrath \& Morrison, 1981; Morrison \& Reilly, 1986; Owsley, Sekuler, \& Siemsen, 1983). Given this age-related reduction in the ability to detect higher spatial frequencies, one might expect that older observers would face a similar difficulty in extracting the spatial information embedded in texture gradients. If so, this would lead to a deterioration in older observers' ability to perceive the slants in depth of 3-D surfaces from patterns of optical texture. One of the primary purposes of the present set of experiments was to evaluate 


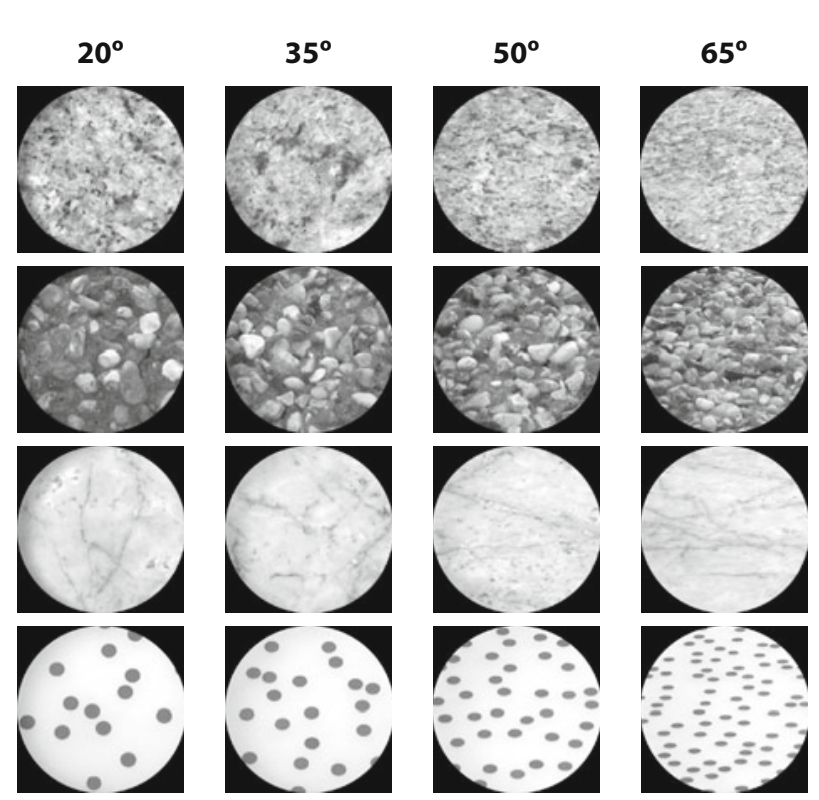

Figure 1. Sample photographs of the textured surfaces that were used as the experimental stimuli in Experiments 1, 2, and 3. Top row, granite; second row from top, pebbles; third row from top, marble; bottom row, circles.

this possibility, since no research has yet been conducted to examine older observers' ability to extract 3-D information from optical patterns of surface texture. A secondary purpose of the present experiments was to compare older observers' ability to perceive surface slant from optical texture (Experiments 1 and 2) with their ability to perceive surface slant from optical patterns of motion parallax and binocular disparity (Experiment 4).

\section{EXPERIMENT 1}

\section{Method}

Apparatus. The observers' slant judgments were made using a palm board (Braunstein, 1968; Creem-Regehr, Gooch, Sahm, \& Thompson, 2004; Gibson, 1950b). On each trial, the observers placed the palm of their right hand on the surface of the palm board and were instructed to adjust the slant of the palm board in depth until its slant matched that of the textured surface (the observers were not able to see their hand during this process; they were required to continuously view the textured surface during the adjustment). The orientations of the palm board (sampled at approximately $100 \mathrm{~Hz}$ ) were monitored by a miniBird 500 position and orientation measurement system (Ascension Technology, Burlington, VT). The miniBird system can measure orientations with a resolution of at least $0.5^{\circ}$. The miniBird system was itself controlled by a Dell Dimension XPS T450 computer.

Stimulus displays. The experimental stimuli were flat, textured surfaces that were viewed at a variety of fixed physical slants, relative to the frontoparallel plane. Three of the four texture types were natural (granite, marble, and a texture composed of pebbles), and the fourth consisted of a random arrangement of circles (the circular texture elements were $7 \mathrm{~mm}$ in diameter). Examples of the textured stimuli are shown in Figure 1, and their Fourier transforms are shown in Figure 2. On every trial, the textures were placed in random orientations with respect to the vertical. The physically slanted surfaces were viewed monocularly through a circular occluding aperture. The textured surface regions that were visible to

the observers subtended $21.8^{\circ}$ visual angle (cf. Todd et al., 2005). The viewing distance from the observers' eye to the nearest part of the textured surfaces was $25 \mathrm{~cm}$; the farthest visible portion of the textured surfaces across the various slant conditions was $50 \mathrm{~cm}$. The observers viewed the texture patterns while using a chinrest in order to prevent head movements.

Procedure. There were a total of 16 distinct experimental conditions formed by the orthogonal combination of four texture types (granite, marble, circle, and pebble textures) and four values of slant $\left(20^{\circ}, 35^{\circ}, 50^{\circ}\right.$, and $65^{\circ}$ relative to the frontoparallel plane; the surface tilt was always vertical, with the top of the textured surface slanted backward; for additional information about surface slant and tilt, see Koenderink, 1986; K. Stevens, 1983). All combinations of texture type and surface slant were presented within a single block of 16 trials; the order of conditions within a block was randomly determined for each individual observer. All of the observers completed five blocks of trials. Each observer thus judged the slants of 80 textured surfaces ( 4 texture types $\times 4$ physical slants $\times 5$ repetitions).

Observers. Thirty-six observers participated in the experiment. Twelve of the observers were 61 years of age or older (mean age, 70.6 years; $S D, 4.7$; range, $61-78)$, and another 24 observers were 27 years of age or younger (mean age, 19.8 years; $S D, 3.1$ ). One of the older observers (age, 75 years) possessed macular degeneration in her left eye. However, her right eye was unaffected, and the visual acuity in that eye was good. Because of the good acuity in her right eye (and the fact that only monocular vision was needed in the present experiment), she was allowed to participate. None of the other observers reported any eye or retinal problems (e.g., macular degeneration, glaucoma, cataracts). The observers' visual acuity was assessed at a distance of $50 \mathrm{~cm}$, using a Landolt C chart (Riggs, 1965). The younger observers' mean acuity was $0.99 \mathrm{~min}^{-1}$, whereas that for the older observers was slightly less, $0.86 \mathrm{~min}^{-1}\left(1.0 \mathrm{~min}^{-1}\right.$ is equivalent to $20 / 20$ vision measured at $20 \mathrm{ft} ; 0.8 \mathrm{~min}^{-1}$ is equivalent to $20 / 25$ vision).

The 24 younger observers were divided into two groups of 12 . One of these groups of younger observers viewed the textured surfaces

Circle

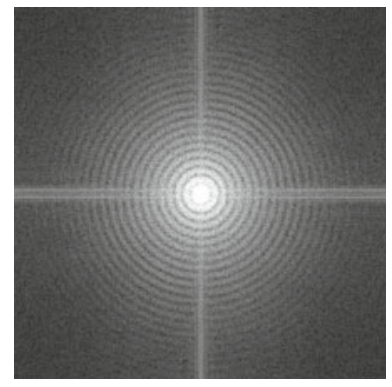

Marble

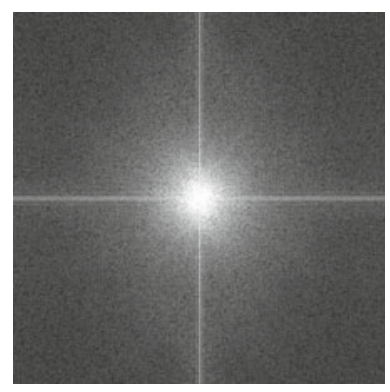

Figure 2. Fourier transforms (contrast enhanced) for the four textures used as stimuli in Experiment 1. 


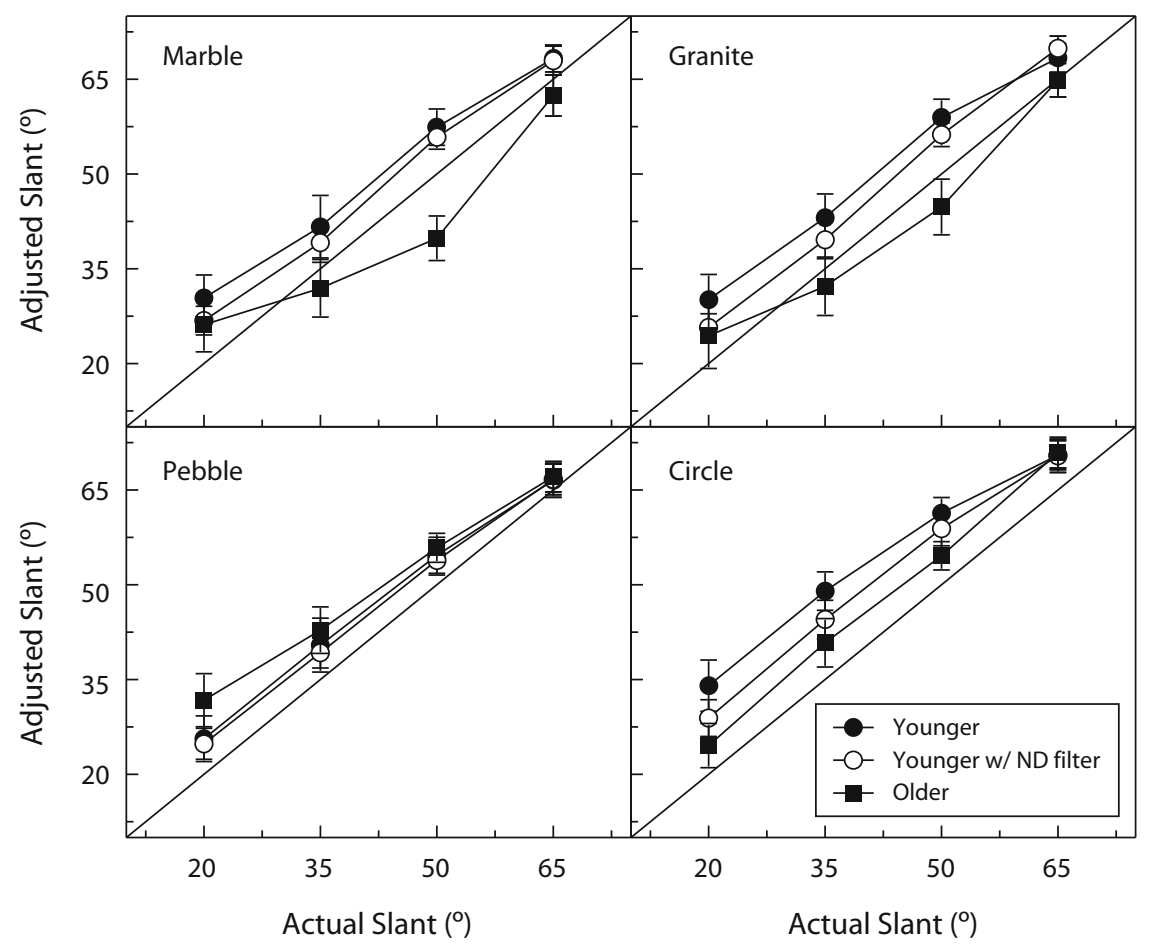

Figure 3. Results of Experiment 1 for the younger and older observers. For each texture type, the observers' adjusted slants are plotted as a function of the actual surface slants. The error bars indicate \pm 1 standard error. Accurate performance is indicated by the solid diagonal line. ND, neutral density.

directly, whereas the other group viewed the textured surfaces using 0.5 neutral-density (ND) filters (Kodak Wratten No. 96). Viewing the surfaces through these ND filters served to reduce the brightness of these younger observers' retinal images by two thirds. This manipulation made their retinal images similar to those of a typical 60 -year-old (see Weale, 1963). The use of ND filters to simulate the optical effects of aging in younger observers has previously been used by other investigators (see, e.g., Bennett et al., 1999; Elliott et al., 1990; Habak \& Faubert, 2000; Sekuler \& Owsley, 1982).

\section{Results and Discussion}

The observers' results are shown in Figures 3-7. Figures 3,4 , and 5 plot the observers' means (i.e., accuracy) for the various conditions, and the nature and magnitude of the observers' variability across repeated trials (i.e., precision) is plotted in Figure 7. The overall results for the three groups of observers are shown in Figure 3. As is clearly evident, there was a large and reliable effect of physical slant: Increases in the physical slant of the textured surfaces produced proportional increases in the perceived slant. This effect of physical slant was confirmed by the results of a three-way ANOVA $[F(3,99)=439.2$, $\left.p<.0001, \eta^{2}=.93\right]$. The variations in physical slant accounted for $63.2 \%$ of the total variance in the observers' judgments. Given that similar past research has shown significant underestimation (e.g., Gibson, 1950b; Rosas et al., 2004; Saunders, 2003), it is interesting that our observers did not exhibit underestimation. In contrast, our observers' judgments of slant were accurate for all three of the natural textures (marble, granite, and pebble tex- tures). The judgments of our observers were less accurate for the manmade circle texture, and they overestimated in this condition (see the lower right panel of Figure 3). This main effect of texture type (circles vs. marble, granite, and pebbles) was statistically significant $[F(3,99)=12.9, p<$ $\left..0001, \eta^{2}=.28\right]$.

As can also be seen in Figure 3, there was no consistent main effect of age $[F(2,33)=1.1, p=.36]$; nor was there any difference between the group of younger observers who viewed the textured patterns while using ND filters and the group of younger observers who did not use the ND filters. However, the age $\times$ texture interaction was significant $\left[F(6,99)=7.8, p<.0001, \eta^{2}=.32\right]$. This interaction is illustrated in Figure 4. One can see from an examination of Figure 4 that whereas the older observers perceived less slant than did the younger observers for the marble, granite, and circle textures, they perceived more slant than did the younger observers for the pebble textures. The differences between the older and the younger age groups were most salient for the marble and pebble textures. For example, the average difference between the perceived slants for the marble and pebble textures was only $1.9^{\circ}$ for the younger observers $\left(48.4^{\circ}\right.$ vs. $46.5^{\circ}$, respectively). In contrast, the difference between the perceived slants for the marble and pebble textures for the older observers was a large $9.3^{\circ}\left(40.1^{\circ}\right.$ vs. $49.4^{\circ}$, respectively).

Both the slant $\times$ texture and the age $\times$ slant $\times$ texture interactions were significant $[F(9,297)=2.7, p<.01$, $\eta^{2}=.08$, and $F(18,297)=2.2, p<.01, \eta^{2}=.12$, respec- 


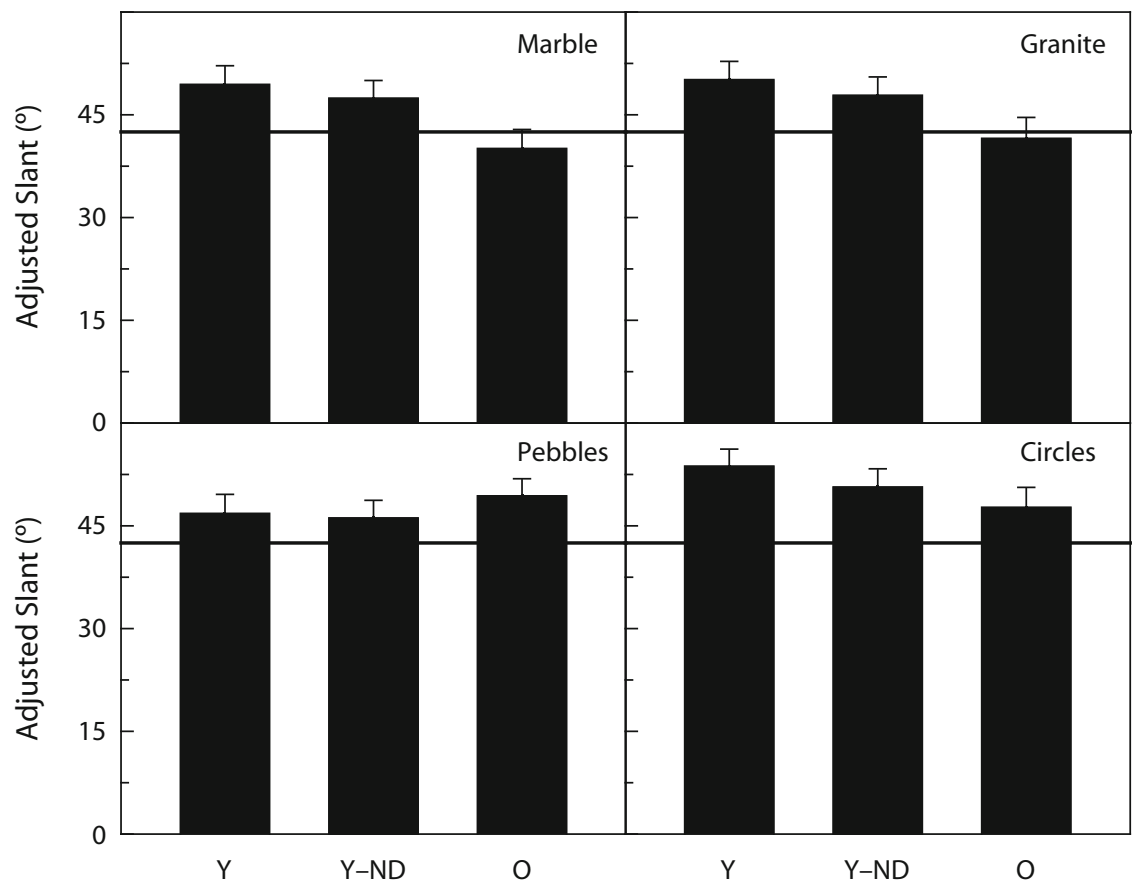

Figure 4. Results of Experiment 1. The younger and older observers' adjusted slants are plotted as a function of texture type. Y, younger observers; Y-ND, younger observers who viewed the stimuli using 0.5 neutral-density filters; $O$, older observers. The error bars indicate \pm 1 standard error. The solid horizontal line (at $\left.42.5^{\circ}\right)$ indicates accurate performance.

tively]. In order to more clearly illustrate the nature of these interactions, Figure 5 plots a subset of the full results that were shown in Figure 3. The slant $x$ texture interaction is readily apparent in the right panel: Note that as the actual slant increased, there was a larger increase in judged slant for the circle textures than for the pebble textures (i.e., the slopes of the curves differ). It is important to note, however, that this slant $\times$ texture interaction occurred only for the older observers. This difference (a slant $\times$ texture interaction for the older observers and no such interaction for the younger observers) was responsible for the observed age $X$ slant $\times$ texture interaction. These interactions, despite being statistically significant, are quite small: Taken together, they account for only $0.7 \%$ of the total variance in the observers' judgments.

In additional analyses, we correlated each individual observer's judged slants with the actual slants. Representative data for 2 observers ( 1 older observer and 1 younger
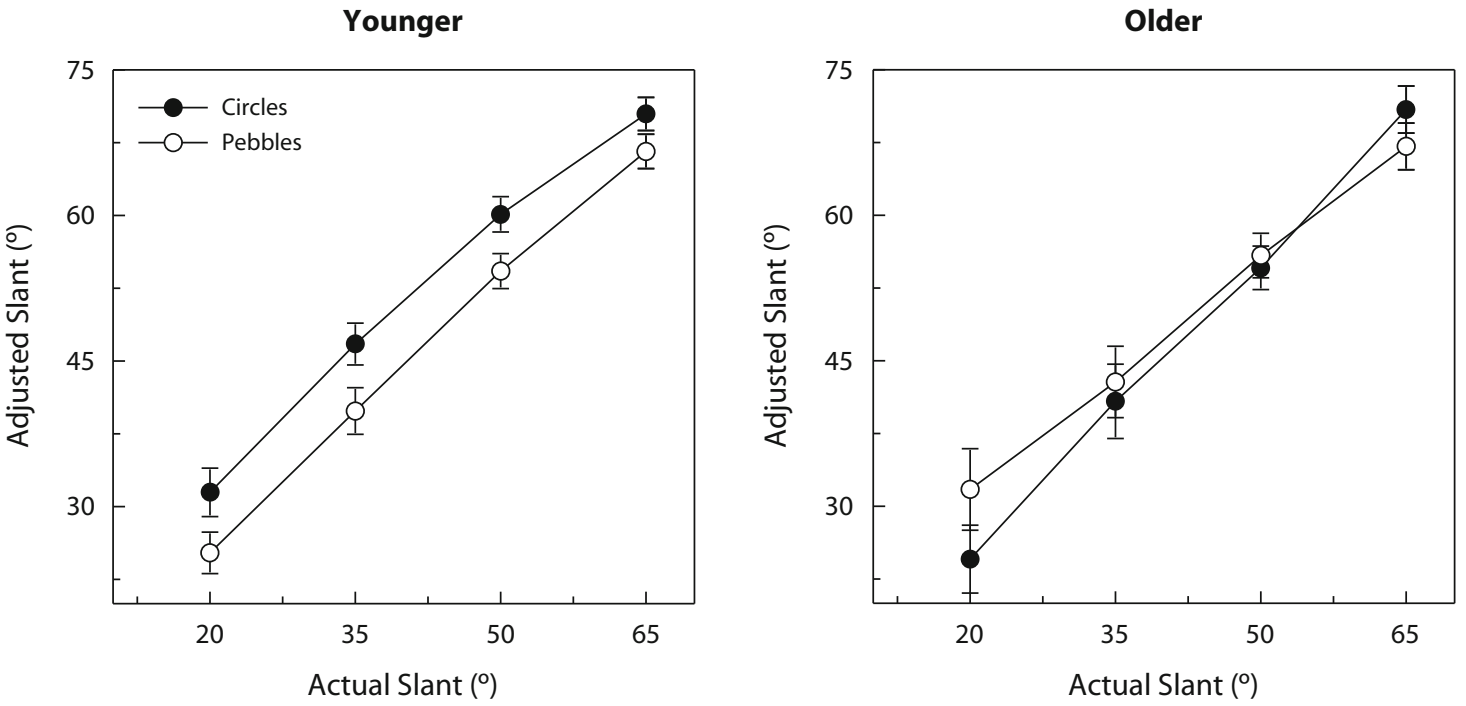

Figure 5. Results of Experiment 1 illustrating the significant slant $\times$ texture and age $\times$ slant $\times$ texture interactions. The error bars indicate \pm 1 standard error. 

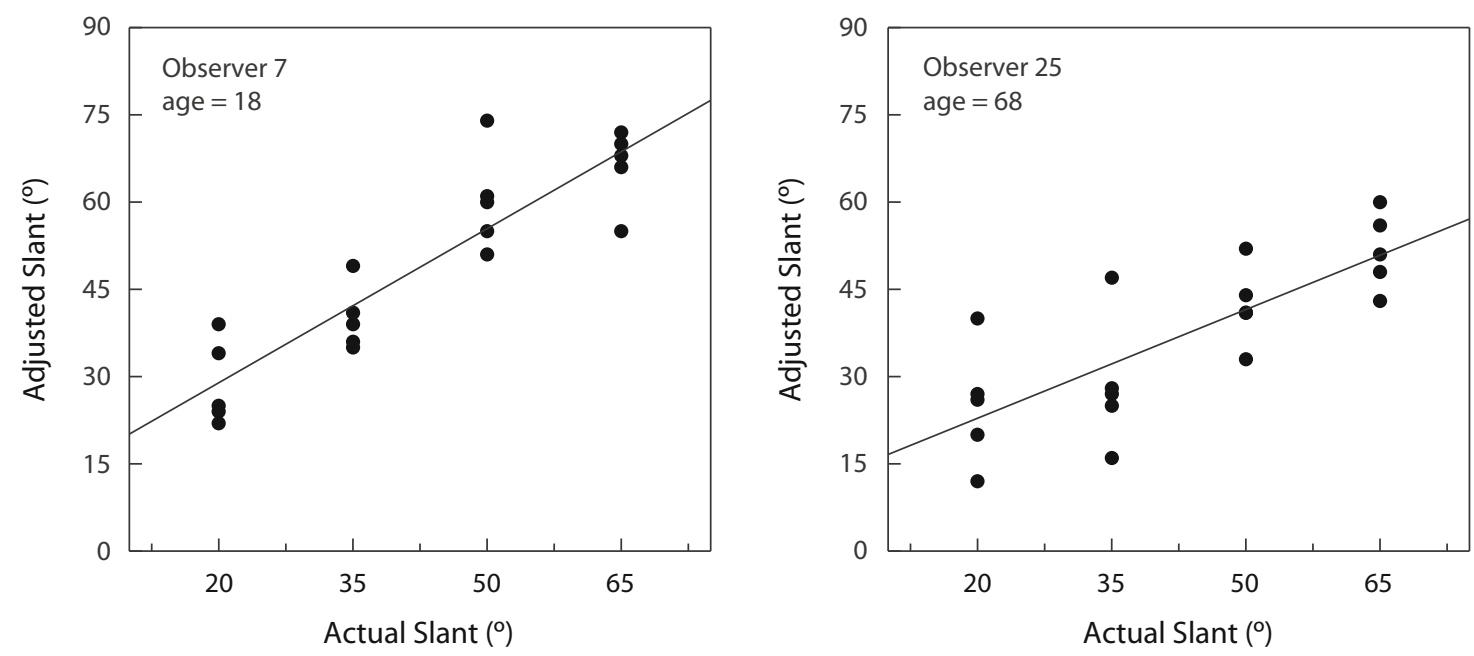

Figure 6. Representative results of Experiment 1 for individual younger and older observers. The best-fitting linear regression lines are also indicated.

observer in the granite texture condition) are plotted in Figure 6. The average Pearson $r$ correlation coefficient was $.9\left(r^{2}=.81\right)$ for the younger observers and $.74\left(r^{2}=.55\right)$ for the older observers. One can see from an inspection of Figure 6 that the judgments of the older observers were less precise (i.e., they exhibited greater variability across repeated judgments for the same experimental condition). To further investigate the apparent age effect on the precision of the observers' judgments, we conducted an ANOVA on the observers' $r^{2}$ values. (The individual $r^{2}$ values indicate how much of the variance in each observer's judgments of slant can be accounted for by changes in physical slant: High $r^{2}$ values indicate high precision and low variability across repeated judgments, whereas low $r^{2}$ values indicate low precision and high variability.) The results of the ANOVA revealed that there was a large effect of age on the precision of the observers' judgments $[F(2,33)=20.0$, $\left.p<.0001, \eta^{2}=.55\right]$. This main effect of age is illustrated in Figure 7. The main effect of texture was significant, as was the age $\times$ texture interaction $[F(3,99)=7.3, p<.001$, $\eta^{2}=.18$, and $F(6,99)=2.4, p<.04, \eta^{2}=.13$, respectively]. The age $\times$ texture interaction can be clearly seen in Figure 7. The precision of the younger observers' judgments was essentially the same for all four surface textures. However, this was not true for the older observers. The older observers' judgments were significantly less precise (i.e., the older observers exhibited more variability across repeated judgments) for the marble textures (the older observers' average $r^{2}$ value was .44 for the marble texture and .6 or higher for the granite, pebble, and circle textures).

\section{EXPERIMENT 2}

The results of Experiment 1 indicate that older observers' monocular judgments of slant from texture are accurate (see Figures 3 and 4). However, the older observers' judgments were more variable and less precise than those of the younger observers (see Figures 6 and 7). Given that the observers made their judgments of slant manually, using a palm board, and that aging is known to lead to deteriorations in fine motor control (e.g., Newell, Vaillancourt, \& Sosnoff, 2006), it is conceivable that the reduced precision that we observed in the older observers was due to a reduction in their motor abilities. The purpose of Experiment 2 was to evaluate the perception of slant from texture by using a dependent measure that had no motor component at all (no palm board, no mouse adjustments, etc.). Accordingly, in the present experiment, we asked our observers to report their perceived slants verbally, using magnitude estimation (S. S. Stevens, 1975). If the older observers' judgments continued to be less precise than those of the younger observers, we can conclude that the choice of method is not responsible and that aging does, indeed, lead to a deterioration in the precision of slant judgments from patterns of optical texture.

\section{Method}

Apparatus. The apparatus was identical to that used in Experiment 1.

Stimulus displays. The stimulus displays were identical to those used in Experiment 1.

Procedure. The experimental conditions and procedures were identical to those used in Experiment 1, with one important exception. In the present experiment, the observers judged the amount of perceived slant by using verbal magnitude estimation. On each trial, the observers were required to provide a verbal estimate of the apparent surface slant, using a scale that ranged from $0^{\circ}$ (surface appeared to be frontoparallel) to $90^{\circ}$ (surface appeared parallel to the observer's line of sight).

Observers. Twelve younger (mean age, 19.5 years; $S D, 3.0$ ) and 12 older (mean age, 73.5 years; $S D=4.7$; range, 67-83) observers participated in the experiment. None of the observers had previously participated in Experiment 1. The younger observers' mean acuity was $1.0 \mathrm{~min}^{-1}$, whereas that for the older observers was slightly less, $0.95 \mathrm{~min}^{-1}$. No observer reported any significant eye disorders, such as macular degeneration, glaucoma, and so forth.

\section{Results and Discussion}

The results are shown in Figures 8-10 (once again, Figures 8 and 9 plot the accuracy of the observers' judgments, 


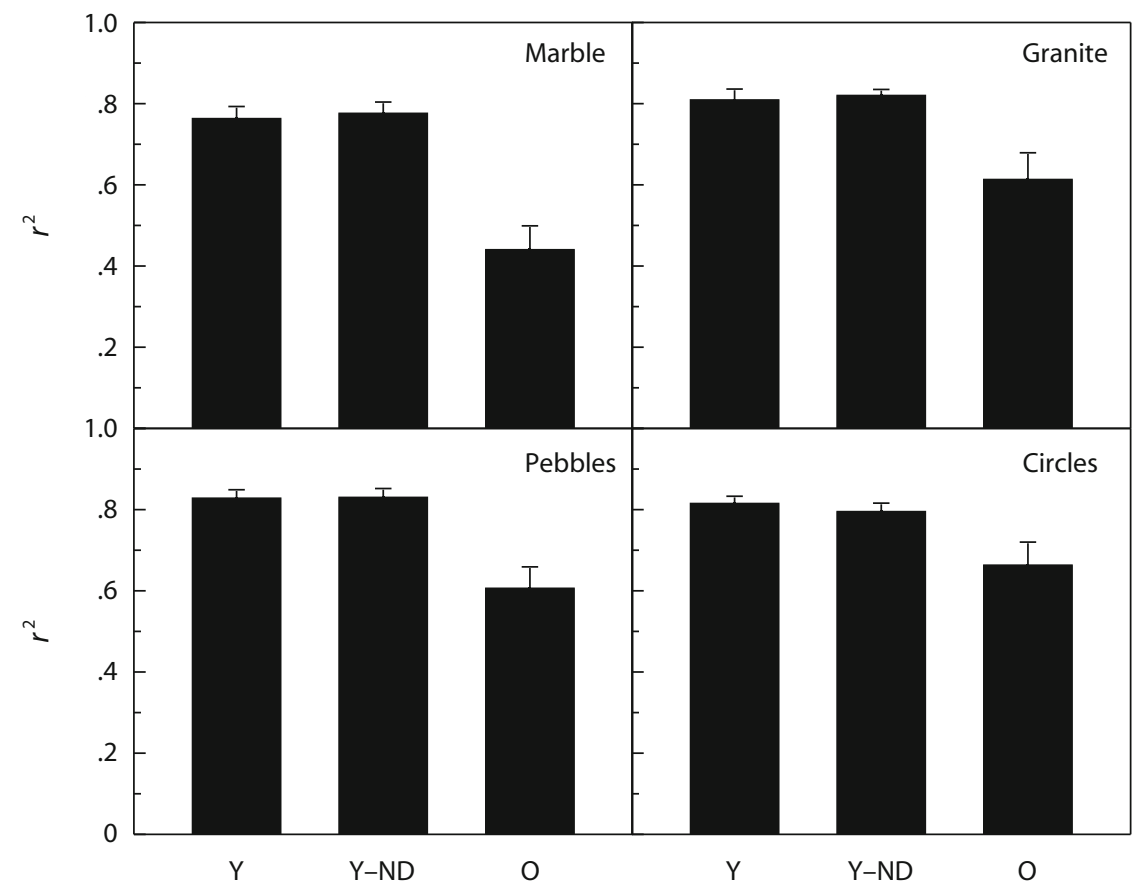

Figure 7. Results of Experiment 1 for the younger and older observers. The observers' $r^{2}$ values (obtained by correlating the actual and the perceived slants) are plotted for each of the four texture types. $\mathrm{Y}$, younger observers; $\mathrm{Y}-\mathrm{ND}$, younger observers who viewed the stimuli using 0.5 neutral-density filters; $O$, older observers. The error bars indicate \pm 1 standard error.

and Figure 10 plots the precision). Figure 8 plots the younger and older observers' adjusted slants as functions of the actual slant and texture type. Once again, the observers' perceived slants increased linearly with increasing physical slants. This effect of physical slant was highly significant and accounted for $56.7 \%$ of the total variance in the observers' judgments $[F(3,66)=114.5, p<.0001$, $\left.\eta^{2}=.84\right]$. It is readily apparent, however, that the observers underestimated in the present experiment. There was also a significant main effect of texture $[F(3,66)=7.6$, $\left.p=.0002, \eta^{2}=.26\right]$, as well as a significant age $\times$ texture interaction $\left[F(3,66)=5.3, p<.01, \eta^{2}=.2\right]$. The nature of this age $\times$ texture interaction can be clearly seen in Figure 8. Whereas there was no effect of age at all for the marble and granite textures, there was a small but significant effect of age for the circle and pebble textures: It is interesting to note that the older observers' judgments were the most accurate in these conditions. Figure 9 illustrates a very small but significant slant $\times$ texture interaction. Note that the rate of increase in the observers' perceived slants with increasing physical slant was larger for circle textures and smaller for pebble textures $[F(9,198)=3.5$, $\left.p<.001, \eta^{2}=.14\right]$.

It is interesting that the slant judgments of the observers in the present experiment (using magnitude estimation) were less accurate than those of the observers in Experiment 1 (who used a motoric judgment involving a palm board). This pattern of results, that observers are often more accurate when making motoric judgments, is well known in the literature. For example, when observers make purely perceptual judgments of distance in depth, they are typically inaccurate (e.g., Lappin, Shelton, \& Rieser, 2006; Loomis, Da Silva, Fujita, \& Fukusima, 1992; Loomis \& Philbeck, 1999; Norman, Crabtree, Clayton, \& Norman, 2005; Norman, Lappin, \& Norman, 2000; Norman, Todd, Perotti, \& Tittle, 1996). However, when observers make their judgments of distance motorically using blindfolded walking, they are typically accurate (e.g., Loomis et al., 1992; Rieser, Ashmead, Talor, \& Youngquist, 1990; Steenhuis \& Goodale, 1988; Thomson, 1983).

As in Experiment 1, we once again correlated each observer's repeated slant judgments for each texture type with the actual surface slants. Pearson $r$ correlation coefficients were once again obtained. If the observers' $r^{2}$ values are high, that would indicate that their repeated judgments of slant were precise (low intrinsic variability; most of the variance in the observers' judgments can be accounted for by changes in the actual surface slant). Conversely, if the observers' $r^{2}$ values are low, that would indicate that their repeated judgments were not precise (a lot of intrinsic variability; a smaller amount of the variance in the observers' judgments can be accounted for by changes in the actual surface slant). The results of the correlational analysis are presented in Figure 10. It is important to note that overall, the observers' judgments were precise despite the use of magnitude estimation. Actual changes in physical surface slant accounted for $60 \%-75 \%$ of the total variance in the observers' verbal estimates of slant. An ANOVA conducted upon the observers' $r^{2}$ values revealed a significant main effect of 


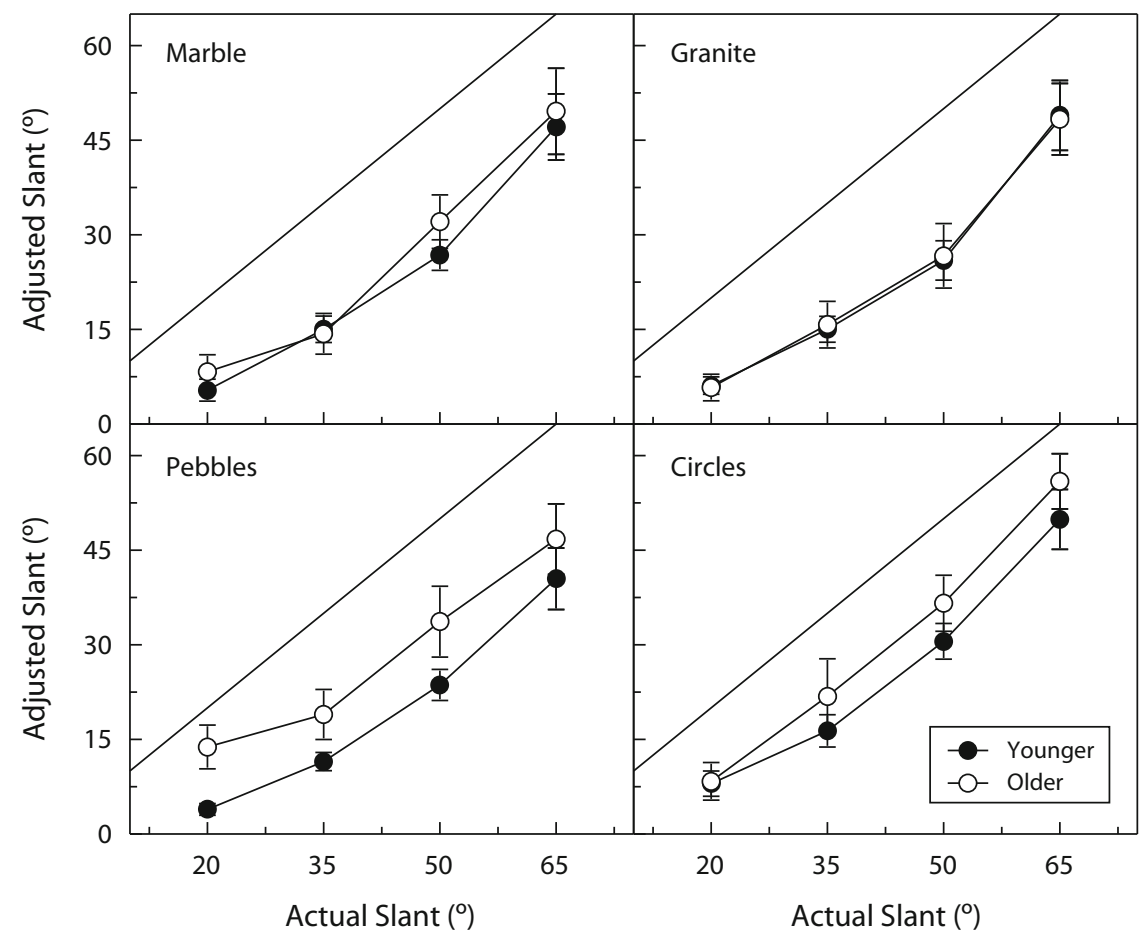

Figure 8. Results of Experiment 2 for the younger and older observers. For each texture type, the observers' perceived slants are plotted as a function of the actual surface slants. The error bars indicate \pm 1 standard error. Accurate performance is indicated by the solid diagonal line.

texture $\left[F(3,66)=5.9, p<.002, \eta^{2}=.21\right]$, as well as a significant age $\times$ texture interaction $[F(3,66)=3.0, p<$ $\left..05, \eta^{2}=.12\right]$. The observers' precision was highest for the circle texture and was lowest for the marble texture. One can readily see in Figure 10 that there were effects of age on precision for all three of the natural texture

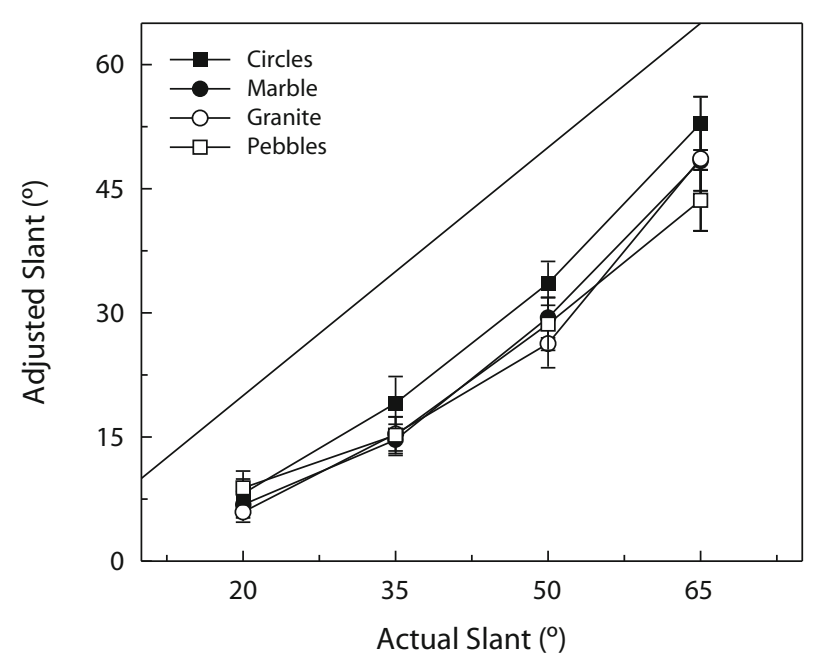

Figure 9. Results of Experiment 2 illustrating the significant slant $\times$ texture interaction. The error bars indicate \pm 1 standard error. Accurate performance is indicated by the solid diagonal line. types (marble, granite, and pebbles). However, the precisions of the two age groups' judgments of slant were equivalent for the circle texture.

In the introduction, we hypothesized that because aging is known to reduce older observers' sensitivity to high spatial frequencies, this might adversely affect older observers' ability to extract and utilize the spatial information in texture gradients in order to perceive slant in depth. Although we did find some age-related deteriorations in performance in Experiments 1 and 2 (e.g., age effects on precision; see Figures 7 and 10), our results, in general, are different from what would have been expected. For example, the circle texture contains the most power at high spatial frequencies, while the marble texture contains the least (see Figure 2). One might have thought, therefore, that any age-related deteriorations in performance would have been largest for the circle texture and smallest for the marble texture. We obtained the opposite pattern of results: Overall, the negative effects of age were smallest for the circle texture and were largest for the marble texture (see, e.g., the results for the marble condition in Figure 7). Many of the older observers told us that it was very difficult to estimate surface slant from the marble textures. For these textures, even though the accuracy of the older observers' slant judgments was as high as that of the younger observers (see Figures 3 and 8), the older observers' repeated judgments were much more variable and imprecise than those of the younger observers (see Figures 7 and 10). 


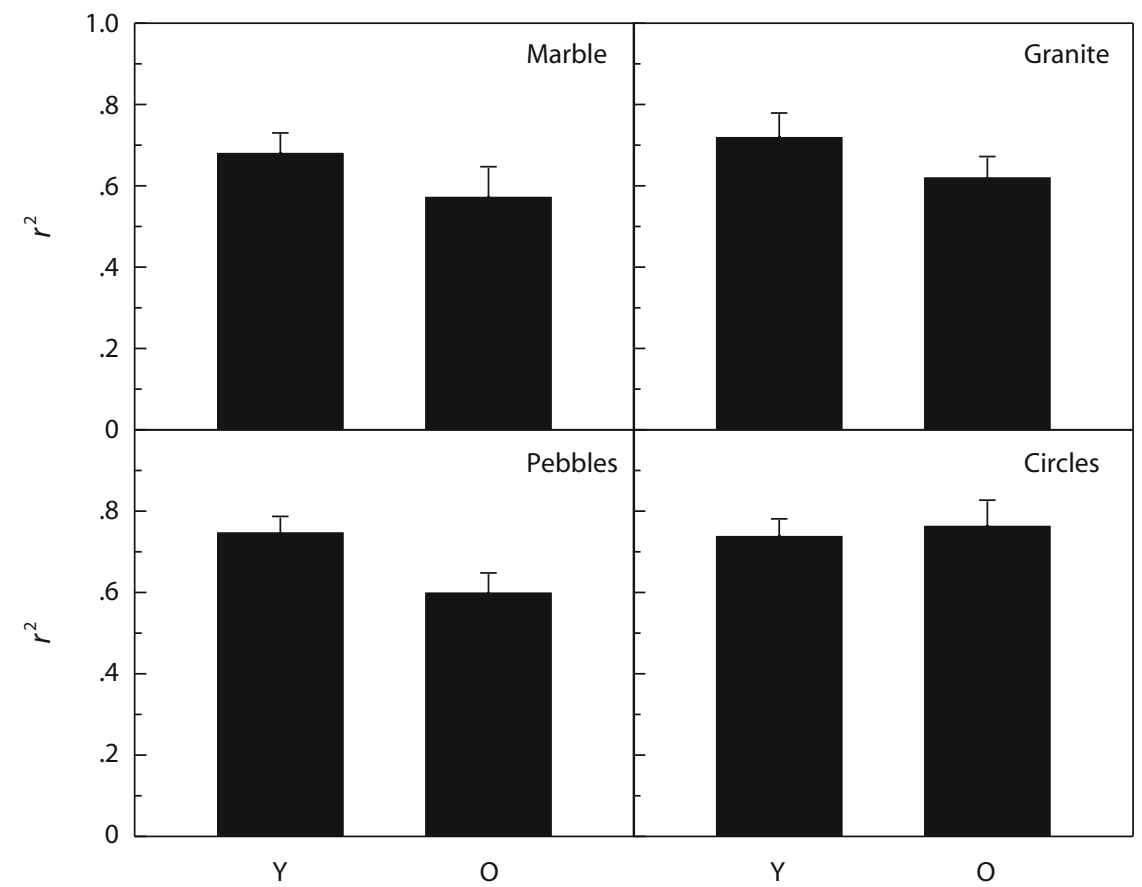

Figure 10. Results of Experiment 2 for the younger and older observers. The observers' $r^{2}$ values (obtained by correlating the actual and the perceived slants) are plotted for each of the four texture types. Y, younger observers; $O$, older observers. The error bars indicate \pm 1 standard error.

\section{EXPERIMENT 3}

The observers' judgments of slant in Experiment 1 (see Figure 3 ) were generally accurate: Our observers did not exhibit the underestimation that has been obtained in many previous studies (see, e.g., Andersen et al., 1998; Rosas et al., 2004; Saunders, 2003; Todd et al., 2005). Given that our surfaces were physically slanted in depth (instead of being simulated computationally and then displayed on a frontoparallel monitor or projection screen), it is possible that other monocular factors, such as accommodative blur (Ciuffreda, Wang, \& Vasudevan, 2007; Frisby, Buckley, \& Horsman, 1995; Watt, Akeley, Ernst, $\&$ Banks, 2005), contributed to the accurate performance of our observers in Experiment 1. Gibson (1950b) acknowledged the possibility that differential blur might contribute to the perception of slant; he stated that "differential blur might be . . . a visual determinant of phenomenal slant, although there is some doubt as to its efficacy" (p. 376). The purpose of the present experiment was to test whether the presence of accommodative blur does contribute to the perception of slant.

\section{Method}

Apparatus. The apparatus was identical to that used in Experiments 1 and 2 .

Stimulus displays. The stimulus displays were identical to those used in Experiments 1 and 2. In this experiment, however, only the granite and circle textures were used.

Procedure. In one of the two viewing conditions, the procedures were identical to those used in Experiment 1. In the other condition, the observers viewed the textured surfaces while using an artificial pupil (0.5-mm diameter); viewing the surfaces through the artificial pupil removed the accommodative blur from the observers' retinal images (see Experiment 2 in Frisby et al., 1995). The usage of artificial pupils also leads to reduced retinal illuminance. We found, however, in Experiment 1 that reductions in retinal illuminance (due to the 0.5 ND filters) had no effect on the observers' judgments. Therefore, any effect of the artificial pupils obtained in the present experiment would probably be due to their effects on accommodative blur.

Observers. Nine observers (mean age, 24.0 years; $S D, 2.2$ ) participated in the experiment. None of the observers had previously participated in either Experiment 1 or 2. The observers' mean acuity was $1.0 \mathrm{~min}^{-1}$. For 3 of the observers, we measured their natural pupil diameters under our lighting conditions; the mean and standard deviation were 3.8 and $0.2 \mathrm{~mm}$, respectively.

\section{Results and Discussion}

The observers' results are shown in Figures 11 and 12. Once again, there was a strong effect of physical slant on the observers' perceived slants $[F(3,24)=92.3, p<$ $\left..0001, \eta^{2}=.92\right]$. There was also a significant effect of the artificial pupils $\left[F(1,8)=13.9, p<.01, \eta^{2}=.64\right]$. As can be seen in Figure 11, the removal of the accommodative blur led to a decrease in perceived slants for both texture types. Changes in the texture also had significant effects: There was a significant main effect of texture, as well as significant slant $\times$ texture and viewing condition $\times$ slant $\times$ texture interactions [texture, $F(1,8)=$ $10.8, p<.02, \eta^{2}=.57$; slant $\times$ texture, $F(3,24)=7.4$, $p=.001, \eta^{2}=.48$; viewing condition $\times$ slant $\times$ texture, $\left.F(3,24)=7.8, p=.001, \eta^{2}=.50\right]$. These main effects and interactions involving texture are evident in the results shown in Figure 12. Note, for example, that there is 


\section{Granite}

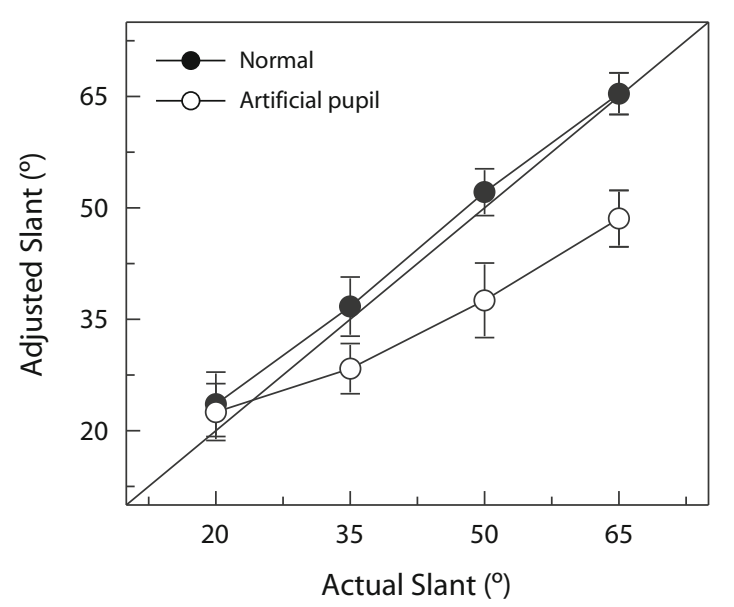

Circles

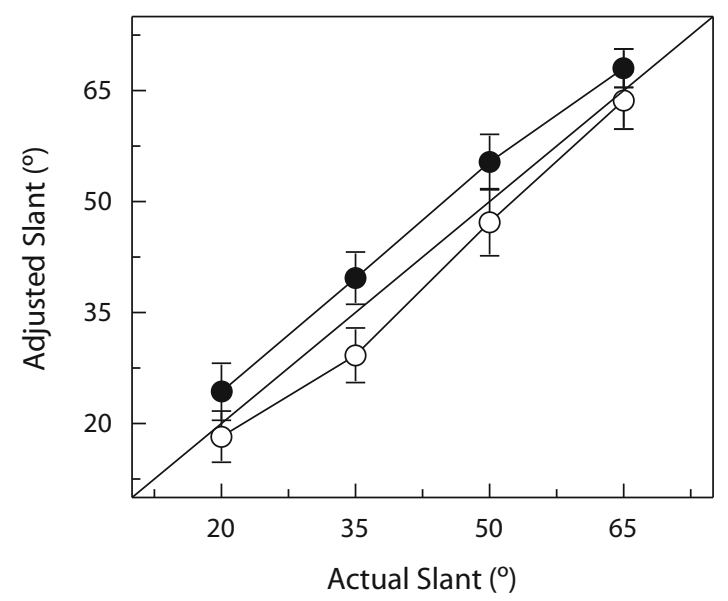

Figure 11. Results of Experiment 3. The observers' adjusted slants are plotted as functions of actual surface slants, texture type, and viewing condition (the observers viewed the stimuli with and without 0.5 -mm artificial pupils). The error bars indicate \pm 1 standard error. Accurate performance is indicated by the solid diagonal line.

an interaction between slant and texture in the right panel (when observers viewed the stimulus patterns through an artificial pupil). This interaction did not occur for normal viewing, thus triggering the viewing condition $X$ slant $X$ texture interaction.

The removal of the accommodative blur (by having the observers view the textured stimuli through an artificial pupil) led to a significant reduction in the observers' perceived slants. This was especially true for the granite texture. In those conditions (Figure 11, open symbols, left panel), the observers exhibited a considerable amount of underestimation. The results of this experiment suggest that the underestimation of slant that is typically observed in experiments involving computer-generated textures is probably due to the lack of blur. Our data also show (present results and Figure 3) that observers' monocular judgments of slant are typically accurate (i.e., no underestima- tion) when the observers view physically slanted surfaces at close range and, thus, can utilize both texture gradients and blur as optical sources of information.

\section{EXPERIMENT 4}

Experiments 1 and 2 showed that older observers' monocular judgments of stationary slanted surfaces were just as accurate as those of much younger observers (see Figures 3 , 4 , and 8 ). Indeed, the older observers' judgments were more accurate than the younger observers for three out of the four texture types in Experiment 1 (see Figure 4) and were more accurate for two of the texture types in Experiment 2 (see Figure 8). When one considers that the older observers in Experiments 1 and 2 were more than 52 years older than the younger observers, this would appear to suggest that the monocular ability to perceive surface slant is quite ro-
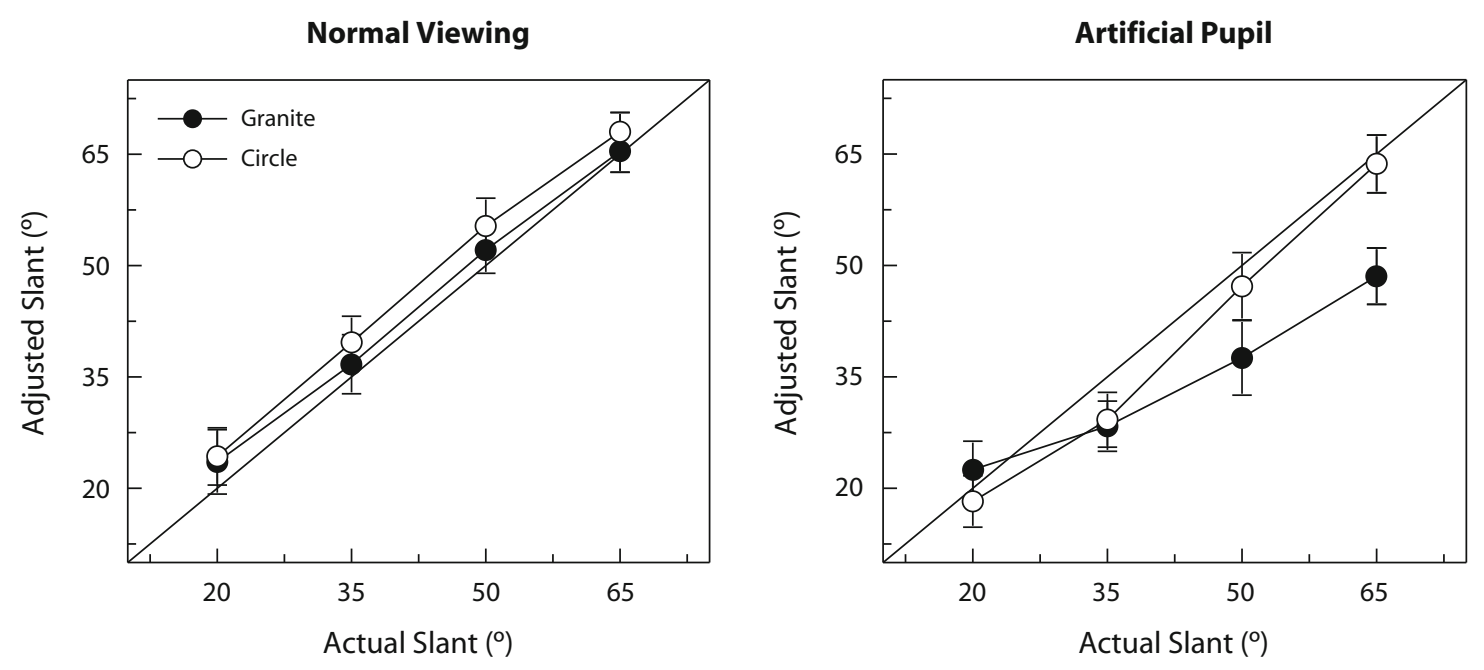

Figure 12. Results of Experiment 3, illustrating the significant slant $\times$ texture and viewing condition $\times$ slant $\times$ texture interactions. The error bars indicate \pm 1 standard error. Accurate performance is indicated by the solid diagonal line. 
bust to the effects of increasing age. Does this age-related similarity in performance also extend to the perception of slanted surfaces defined by motion and binocular disparity? Past research has frequently shown that older observers' performance is reduced for tasks involving the detection and discrimination of surfaces defined by motion and binocular disparity (Andersen \& Atchley, 1995; Laframboise, De Guise, \& Faubert, 2006; Norman et al., 2004; Norman, Crabtree, Herrmann, et al., 2006; Norman, Dawson, \& Butler, 2000). The purpose of the present experiment was to evaluate the effects of age on the perceived slant of stereoscopic and motion-defined surfaces.

\section{Method}

Apparatus. In this experiment, the stereoscopic surfaces were generated by the same Dell Dimension XPS T450 computer that was used to measure the orientation of the palm board. An Apple PowerMacintosh G4 computer was used to generate the motiondefined surfaces. All of the stimuli were then presented on a 22 -in. Mitsubishi Diamond Plus 200 color monitor $(1,280 \times 1,024$ pixel resolution). The observers viewed all of the stimuli using a chinrest, so that their heads remained stationary.

Stimulus displays. The slanted surfaces were defined by the disparities and motions of high-contrast points presented against a black background. The stimulus displays subtended $21.8^{\circ}$ and were viewed through a circular aperture. The viewing distance was $71.5 \mathrm{~cm}$ (a distance of $71.5 \mathrm{~cm}$ was necessary for the motion- and disparity-defined surfaces to have the same projected size as the surfaces used in the previous experiments). The dotted patterns possessed either a high density of $7.7 \mathrm{dots} / \mathrm{deg}^{2}$ or a low density of $0.77 \mathrm{dots} / \mathrm{deg}^{2}$. Given that the area of the aperture was $375 \mathrm{deg}^{2}$, approximately 2,900 (high-density) or 290 (low-density) points were visible within the aperture at any moment in time.

The stereoscopic stimuli were presented as anaglyphs (as in our most recent experiments on aging and stereopsis; see Norman, Crabtree, Herrmann, et al., 2006). The surface points presented to one eye were rendered in red, and the points presented to the other eye were rendered in green. The observers wore glasses with red/green filters, so that each eye's view contained only the points appropriate for that eye. The slanted surfaces in the motion conditions translated orthogonally to the observers' line of sight (i.e., left or right) at a speed of $15 \mathrm{~cm} / \mathrm{sec}(12 \mathrm{deg} / \mathrm{sec})$. Because the rendering included perspective and the surfaces were oriented so that the top of the surface was slanted back in depth, the resulting moving pattern contained a gradient of projected speeds (i.e., faster speeds at the bottom and slower speeds at the top).

The slant of the depicted surfaces was defined only by the pattern of projected speeds or binocular disparities: The points were spatially distributed homogeneously within the 2-D projected images that were displayed on the monitor (i.e., there were no texture element density gradients that might serve as a source of information for slant). Our moving stimuli were thus similar to those in Braunstein (1968); he also depicted slanted surfaces by using a speed gradient, with no accompanying gradient of texture element density.

Procedure. A total of four experimental conditions were formed by the orthogonal combination of two stimulus types (surfaces defined by motion vs. binocular disparity) and two surface point densities ( 7.7 vs. 0.77 points $/ \mathrm{deg}^{2}$ ). Separate blocks of trials were run for each of these four experimental conditions. The order of these blocks was counterbalanced across observers. Within any given block of trials, each of the surface slants $\left(20^{\circ}, 35^{\circ}, 50^{\circ}\right.$, and $\left.65^{\circ}\right)$ was presented five times; each block thus contained 20 trials. Within each block, the order of surface slants was randomly determined. By the end of the experiment, each observer had estimated the slants of 80 surfaces. On any given trial, the observers' task was the same as that in Experiment 1: They were required to place their right hand upon the palm board and to adjust its orientation until it matched that of the depicted surface (the observers were unable to see their hand during this adjustment process).

Observers. Twenty observers participated in the experiment. Ten of the observers were 63 years of age or older (mean age, 73.6 years; $S D, 5.7$; range, 63-82), and another 10 observers were 22 years of age or younger (mean age, 19.2 years; $S D, 1.6$ ). All of the observers were screened to ensure that they possessed stereopsis. We showed them random-dot stereograms depicting a variety of curved surfaces (we used the same curved surfaces that were utilized in Experiment 1 in Norman et al., 2004); all of the observers were able to spontaneously describe the 3-D shape of the depicted surfaces, thus demonstrating stereopsis. None of the observers had previously participated in Experiment 1, 2, or 3. No observers reported any eye or retinal problems (e.g., macular degeneration, glaucoma, cataracts, etc.). The younger observers' mean acuity was $1.0 \mathrm{~min}^{-1}$, and that for the older observers was slightly less, $0.96 \mathrm{~min}^{-1}\left(1.0 \mathrm{~min}^{-1}\right.$ is equivalent to $20 / 20$ vision measured at $20 \mathrm{ft} ; 0.8 \mathrm{~min}^{-1}$ is equivalent to $20 / 25$ vision).
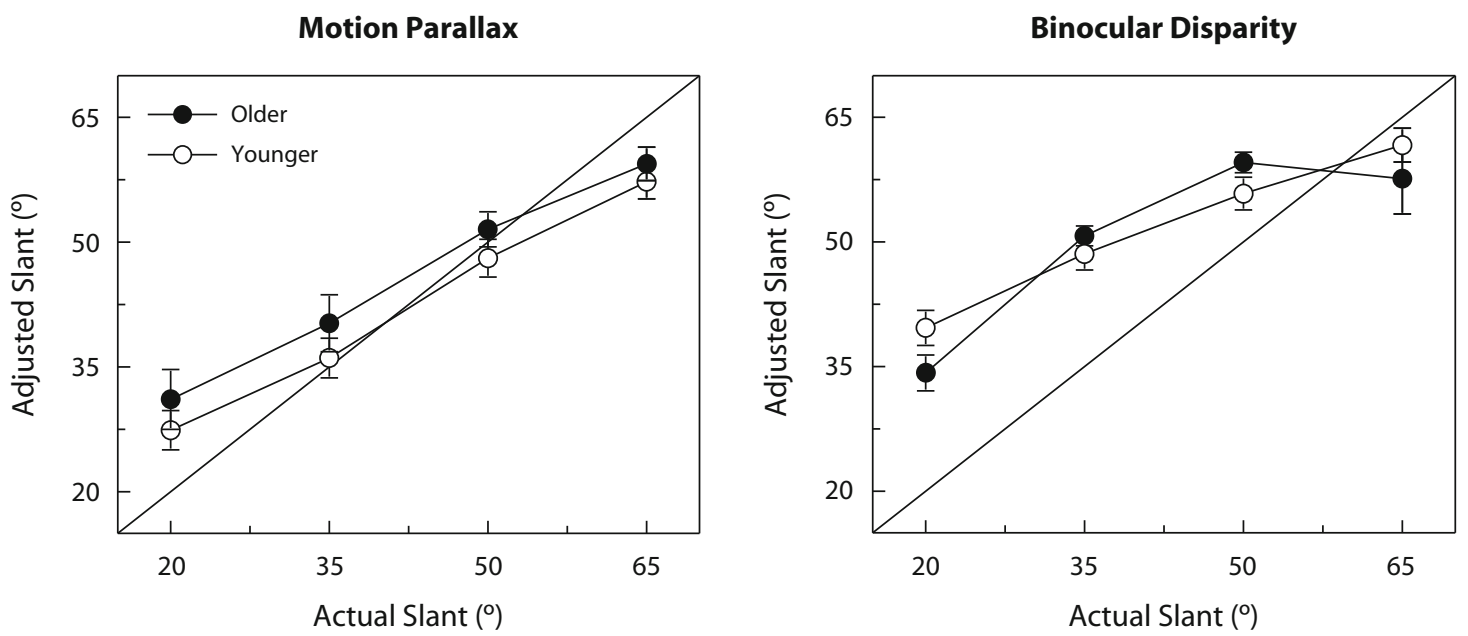

Figure 13. Results of Experiment 4. The younger and older observers' adjusted slants are plotted as functions of simulated slant and stimulus type (binocular disparity vs. motion-defined surfaces). The error bars indicate \pm 1 standard error. Accurate performance is indicated by the solid diagonal line. 


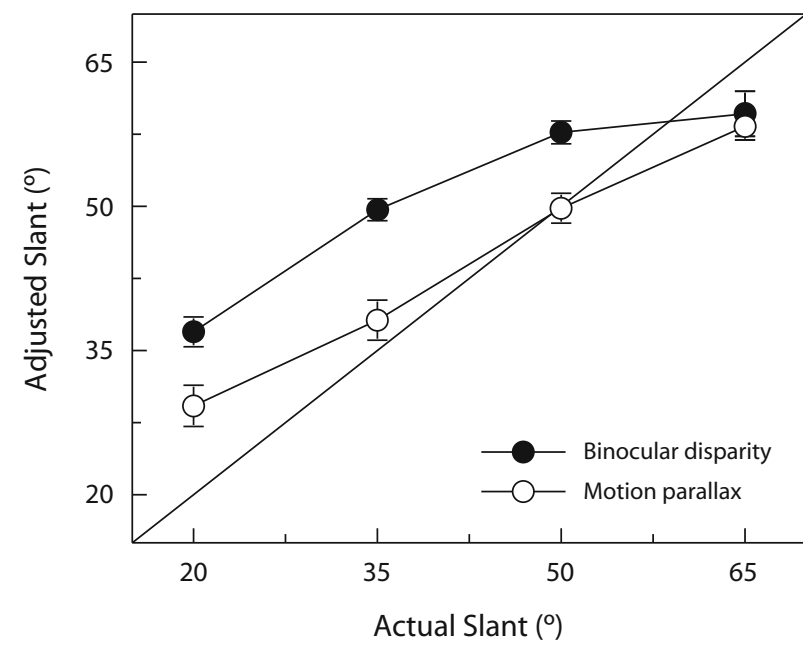

Figure 14. Results of Experiment 4, illustrating the significant stimulus type (binocular disparity vs. motion) $\times$ slant interaction. The error bars indicate \pm 1 standard error. Accurate performance is indicated by the solid diagonal line.

\section{Results and Discussion}

Various aspects of the observers' results are shown in Figures 13-18 (Figures 13-16 plot the accuracy of the observers' judgments, and Figure 18 plots the precision). The observers' adjusted slants are plotted for each age group and stimulus type in Figure 13. There were no effects of age: Neither the main effect nor any of the interactions were significant [e.g., main effect, $F(1,18)=$ $\left.0.1, p=.72, \eta^{2}=.007\right]$. It is readily evident from an inspection of Figure 13 that the observers' judged slants increased as a function of the actual slants $[F(3,54)=$ $\left.80.3, p<.0001, \eta^{2}=.82\right]$. However, it is also clear that the observers' rate of increase in perceived slant (relative to changes in the actual slant) was less than that obtained in Experiment 1 (see Figure 3). In Experiment 1, as the actual slants changed by $45^{\circ}$ (from $20^{\circ}$ to $65^{\circ}$ ), the observers' perceived slants changed by $40^{\circ}$ (from $27.8^{\circ}$ to $67.8^{\circ}$ ). In the present experiment, as the actual slants changed by $45^{\circ}$ (also from $20^{\circ}$ to $65^{\circ}$ ), the observers' perceived slants changed by a smaller $25.9^{\circ}$ (from $33.1^{\circ}$ to $\left.59.0^{\circ}\right)$. The difference in the rate of increase in perceived slant between Experiment 1 and the stereoscopic condition in the present experiment was significant $\left[F(1,40)=12.1, p=.001, \eta^{2}=.23\right]$. This difference in rate of increase in perceived slant was also significant between the results of Experiment 1 and the motion condition in the present experiment $[F(1,40)=7.6, p<$ $\left..01, \eta^{2}=.16\right]$.

In addition to the main effect of slant, there was a significant main effect of stimulus type [binocular disparity vs. motion $\left.F(1,18)=20.7, p=.0002, \eta^{2}=.54\right]$, so that the observers' perceived slants were higher for the stereoscopic surfaces, particularly at the lower simulated slants. This main effect of stimulus type can be seen in Figure 14; the interaction of stimulus type and slant was also significant $\left[F(3,54)=7.9, p=.0002, \eta^{2}=.3\right]$, and this interaction is also evident in the results shown in Figure 14.
The ANOVA revealed that although there was no significant main effect of density $[F(1,18)=1.2, p=.29$, $\left.\eta^{2}=.06\right]$, there were two significant interactions involving density. The density $\times$ slant interaction $[F(3,54)=$ 4.5, $\left.p<.01, \eta^{2}=.2\right]$ is illustrated in Figure 15, and the density $\times$ stimulus type interaction $[F(1,18)=13.2$, $\left.p=.002, \eta^{2}=.42\right]$ is presented in Figure 16. One can see in Figure 15 that for the high-density surfaces, the observers' perceived slants continued to increase as the actual slant was changed from $50^{\circ}$ to $65^{\circ}$. The observers' perceived slants for the low-density surfaces, however, asymptoted at the higher actual slants. This difference (linear increase vs. asymptote) is responsible for the observed density $\times$ slant interaction. Figure 16 shows that the effect of increases in density was different for the stereoscopic and the motion-defined surfaces. As the surface point density increased, that led to a decrease in perceived slant for the motion-defined surfaces, but not for the stereoscopic surfaces. It is important to note, in this context, that the most accurate performance occurred when the observers judged the slants of the highdensity moving surfaces.

In order to evaluate the precision of the observers' judgments, we once again correlated each observer's adjusted slants with the actual slants. Figure 17 plots one older observer's ( 77 years of age) adjusted slants for the low-density stereoscopic condition. It is clear from this observer's results that he could not reliably see a slanted surface in depth when the simulated slant was $65^{\circ}$ : For four out of the five repeated trials, the gradient of binocular disparities was apparently too high for this observer. This inability to reliably perceive surface slant from high binocular disparity gradients occurred for half of the older observers and 2 of the younger observers. For these observers, we did not include their judgments for the $65^{\circ}$ slant condition in the correlational analyses, because they were unable to perceive slant from these patterns

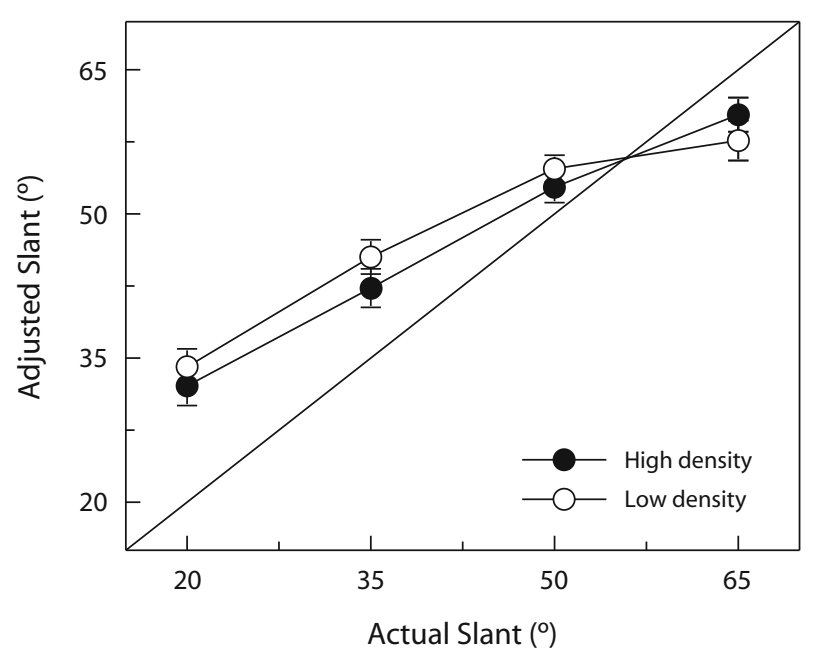

Figure 15. Results of Experiment 4, illustrating the significant density $\times$ slant interaction. The error bars indicate \pm 1 standard error. Accurate performance is indicated by the solid diagonal line. 


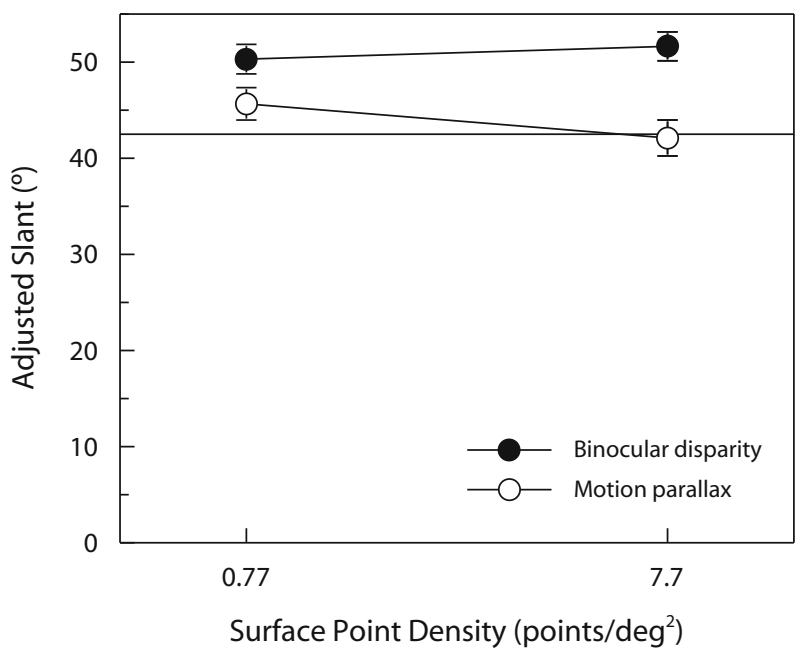

Figure 16. Results of Experiment 4, illustrating the significant density $\times$ stimulus type (binocular disparity vs. motion) interaction. The error bars indicate \pm 1 standard error. Accurate performance is indicated by the horizontal line.

reliably. In Figure 17, the solid line indicates the bestfitting regression line for those stimulus patterns that the observer was able to perceive reliably (the slope of this best-fitting regression line is 1.134 , whereas it would have been -0.082 if we had included the judgments for the $65^{\circ}$ condition). The average Pearson $r$ correlation coefficients were .79 for the younger observers and .77 for the older observers. The precision of the observers' judgments (i.e., $r^{2}$ values) are plotted in Figure 18 for the four different experimental conditions. The only variable to have a significant effect on the precision of the observers' judgments was density $\left[F(1,18)=6.7, p<.02, \eta^{2}=\right.$ .27]: The average $r^{2}$ value was .68 for the high-density surfaces and .6 for the low-density surfaces. One can see from a comparison of Figures 7 and 18 that the precision of the observers' judgments was similar for both Experiments 1 (perceived slant from texture) and 4 (perceived slant from binocular disparity and motion). The overall difference in precision between Experiments 1 and 4 was not significant [binocular disparity vs. texture, $F(1,40)=0.1, p=.72, \eta^{2}=.003$; motion vs. texture, $\left.F(1,40)=2.6, p=.12, \eta^{2}=.06\right]$.

\section{GENERAL DISCUSSION}

The results of Experiments 1 and 2 clearly showed that the observers' monocular judgments of slant from optical patterns of texture correlated highly with the actual surface slants (see Figures 3 and 8). Given that aging is known to produce quantitative reductions in performance for a variety of 3-D tasks involving the utilization of binocular disparity (Laframboise et al., 2006; Norman, Crabtree, Herrmann, et al., 2006; Norman, Dawson, \& Butler, 2000; Norman et al., 2008), motion (Andersen \& Atchley, 1995; Norman et al., 2004; Norman, Dawson, \& Butler, 2000), lambertian shading (Norman \& Wiesemann, 2007), and specular highlights (Norman \& Wiesemann, 2007), it is interesting and important to find in the present experiments that the older observers' judgments of slant from texture were just as accurate as the judgments produced by the younger observers (see, e.g., Figures 3 and 4). Figure 4 shows that the older observers were, in fact, more accurate than the younger observers for three out of the four texture types (i.e., marble, granite, and circles). It would appear that texture is an important source of optical information that can be effectively utilized by older observers, even those as old as 78-83 years (the oldest observers in our study).

The results of Experiments 1 and 2 did demonstrate, however, that increases in age led to a reduction in the precision of the older observers' repeated judgments of surface slant from textured patterns (see Figures 6, 7, and 10). The older observers did exhibit more variability in their repeated judgments of slant from texture, regardless of the particular mode of response. Because both motoric (Experiment 1, Figure 7) and nonmotoric (Experiment 2, Figure 10) judgments led to significant reductions in precision for the older observers, it appears that increasing age is associated with increases in the variability of perceived slant from texture (i.e., the cause of the reduced precision in Experiment 1 is probably not connected to any agerelated motor difficulty in adjusting the palm board, because the older observers also exhibited reduced precision for most of the texture types in Experiment 2 with purely verbal judgments). Another reason for believing that the reduced precision obtained in Experiment 1 for the older observers was not due to any motoric difficulty in using the palm board is the finding in Experiment 4 (perceived slant from motion and binocular disparity) of similar precisions for younger and older observers (see Figure 18).

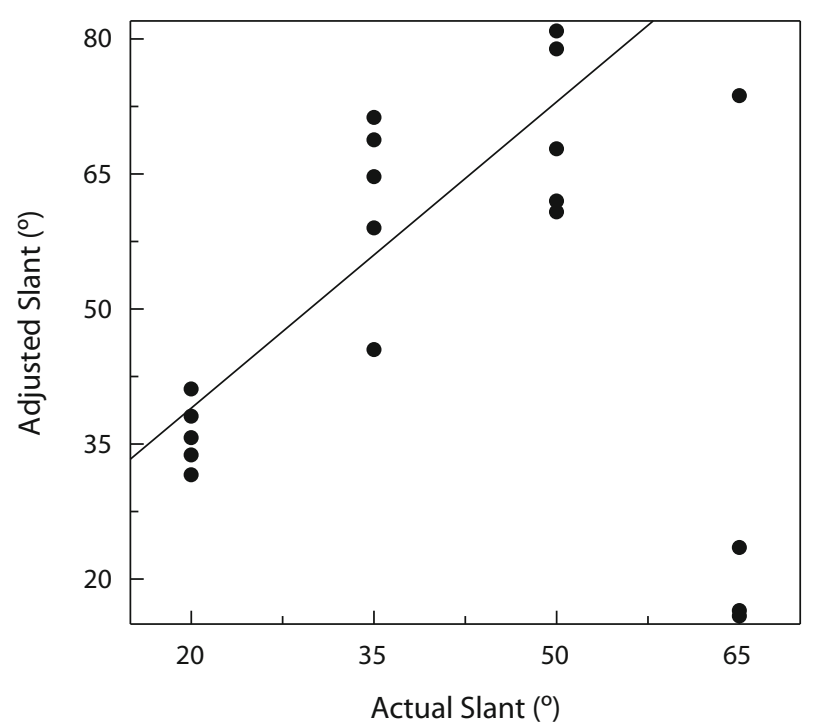

Figure 17. Results for 1 individual older observer (77 years of age), obtained for the stereoscopic, low-density condition. The observer's adjusted slants are plotted as a function of the actual surface slants. The solid line indicates the best-fitting regression line (not including the $65^{\circ}$ simulated slants, which the observer could not see reliably). 


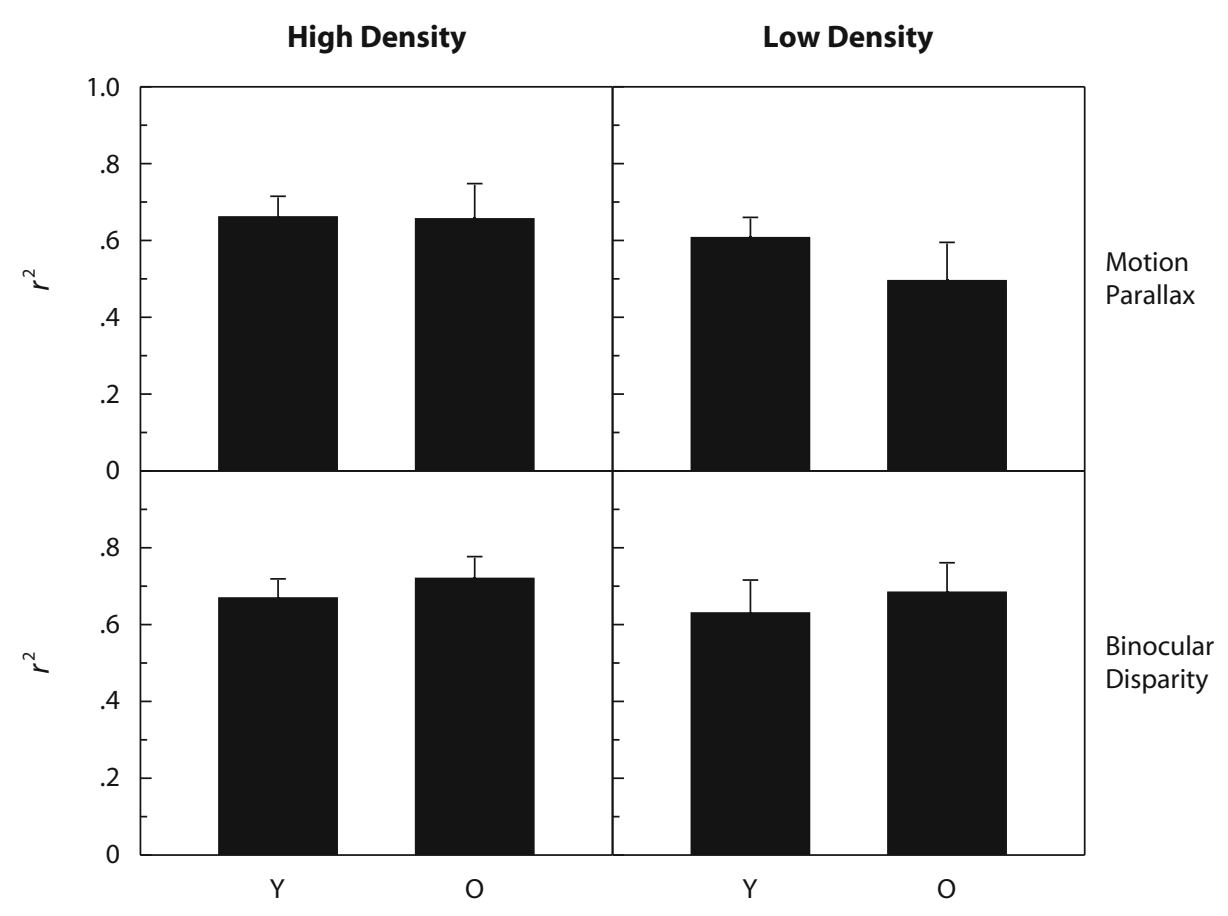

Figure 18. Results of Experiment 4 for the younger and older observers. The observers' $r^{2}$ values (obtained by correlating the simulated and the perceived slants) are plotted for each of the four combinations of surface point density and stimulus type. $Y$, younger observers; $O$, older observers. The error bars indicate \pm 1 standard error.

Experiment 4 was conducted to assess younger and older observers' ability to perceive surface slant from computer-generated patterns containing binocular disparity or motion and to compare the resulting performances with those obtained for the textured surfaces in Experiment 1 . The results of Experiment 4 were similar to those obtained in Experiment 1 in that the observers' perceived slants increased as the simulated slant was increased. It is interesting to note, however, that the slopes (rate of increase in perceived slant, relative to changes in simulated slant) obtained with the computer-generated surfaces were less than those obtained with the physically slanted textured patterns (cf. Figures 13 and 3). The mean slope for Experiment 1 (texture patterns) was 0.87, whereas those for Experiment 4 were 0.65 and 0.66 for the binocular disparity and motion-defined surfaces, respectively. Such reduced slopes have also been obtained in past research. Both van Ee (2001; see the left panel of his Figure 4) and Bradshaw, Hibbard, van der Willigen, Watt, and Simpson (2002; see their Figure 4) found that the rate of increase in perceived slant (relative to increases in simulated slant) was considerably less than 1.0. Our stereoscopic results are especially close to those in Bradshaw et al. (see their Figures 4A and 4C). Braunstein (1968) used motion gradients similar to ours (speed gradients with no accompanying texture element density gradients) and also found low slopes. Braunstein found that as he increased the motionspecified slants from $0^{\circ}$ to $60^{\circ}$, his observers' perceived slants increased from $1.7^{\circ}$ to $20.7^{\circ}$. Our observers' judgments (see the left panel of Figure 13) were considerably more accurate than those obtained by Braunstein (our observers' mean slope was 0.66 , whereas the slope obtained by Braunstein was 0.32 ; perfectly accurate performance would be indicated by a slope of 1.0).

Past research on the perception of slant, conducted mostly with computer-generated texture patterns, has typically shown underestimation (e.g., Andersen et al., 1998; Gibson, 1950b; Newman et al., 1973; Rosas et al., 2004; Saunders, 2003; Todd et al., 2005). The observers in our Experiment 2 also exhibited underestimation when they judged the surface slants by using magnitude estimation (see Figure 8). The accurate judgments that were obtained in Experiment 1 (see Figure 3) for the three natural texture types (marble, granite, and pebbles) are therefore interesting, because accuracy in slant estimation has rarely been demonstrated in prior research (see, however, the results of Zimmerman, Legge, \& Cavanagh, 1995). The results of Experiment 3 suggest that accommodative blur contributes to the perception of slant; when it was removed from the observers' retinal images, their perception of the surface slant decreased (see Figure 11). Our results are thus consistent with those of Ciuffreda et al. (2007), Frisby et al. (1995), and Watt et al. (2005), who suggested that retinal blur serves as an important source of information supporting the perception of surface slant and depth.

To conclude, we found in the present investigation that older observers' perceptual judgments of surface slant were as accurate as those of much younger observers. Furthermore, this similarity in performance was obtained 
for all of the surface types that were investigated (surfaces defined by binocular disparity, as well as those defined by monocular patterns of texture or motion). This similarity in performance with regard to accuracy might seem surprising, given the well-established fact that aging is known to reduce older observers' sensitivity to higher spatial frequencies (when the task is to detect the presence or absence of simple sine-wave luminance gratings; see, e.g., Owsley et al., 1983). Our results suggest that the knowledge of an older observer's contrast sensitivity function does not necessarily allow us to predict how well that observer can perceive the 3-D slants of environmental surfaces. Parallel findings occur in haptics; Norman, Crabtree, Norman, et al. (2006; see Figure 3) found that there was no relationship between an older observer's tactile acuity and his or her performance on a 3-D shape discrimination task. Gibson (1950a; see pp. 84-85, 92-93, and 172-173) identified two sources of information about slant that are contained within projected images of textured surfaces. The first potential source of information about slant is provided by changes in texture element density. Given a homogeneously textured surface, when its orientation is frontoparallel, there will be no changes in texture element density across its projected image; when the surface is slanted in depth, however, the change in texture element density across the projected image varies with the magnitude of the slant (higher slants result in larger changes in texture element density). The second potential source of information about slant involves changes in the projected shape of texture elements. Consider a planar surface covered with circular texture elements. When the surface orientation is frontoparallel, the projected texture elements are also circular. However, when the surface is slanted in depth, the projected texture elements become elliptical. The eccentricity of the projected elliptical texture elements becomes greater as the slant of the surface in depth is increased (see, e.g., the bottom row of Figure 1). The results from our Experiments 1 and 2 (see Figures 3 and 8) suggest that older observers can effectively utilize both of these potential sources of information about slant. The accurate performance for the granite textures indicates that older observers are sensitive to texture element density gradients, and the older observers' accurate performance for the circle textures suggests that they can also use the eccentricity of the projected texture elements to estimate surface slant. Perhaps the most interesting finding of our experiments, however, does not involve age: Our present results indicate that texture gradients (perhaps in conjunction with other monocular sources of information, such as accommodative blur) may be more effective sources of information about surface slant than are gradients of either binocular disparity or motion (cf. Figures 3 and 13). It appears to us that J. J. Gibson (1950a, 1950b) was correct in pointing out the importance of texture gradients for the perception of environmental slant.

\section{AUTHOR NOTE}

We thank Jocelyn Faubert and an anonymous reviewer for their helpful comments on an earlier version of the manuscript. Correspondence concerning this article should be addressed to J. F. Norman, Department of Psychology, Western Kentucky University, Bowling Green, KY 42101 (e-mail: farley.norman@wku.edu).

$$
\text { Note-Accepted by the previous editorial team, }
$$
when Thomas H. Carr was Editor.

\section{REFERENCES}

Andersen, G. J., \& Atchley, P. (1995). Age-related differences in the detection of three-dimensional surfaces from optic flow. Psychology \& Aging, 10, 650-658.

Andersen, G. J., Braunstein, M. L., \& Saidpour, A. (1998). The perception of depth and slant from texture in three-dimensional scenes. Perception, 27, 1087-1106.

Arundale, K. (1978). An investigation into the variation of human contrast sensitivity with age and ocular pathology. British Journal of Ophthalmology, 62, 213-215.

Bennett, P. J., Sekuler, A. B., \& OzIn, L. (1999). Effects of aging on calculation efficiency and equivalent noise. Journal of the Optical Society of America A, 16, 654-668.

Bradshaw, M. F., Hibbard, P. B., van der Willigen, R., Watt, S. J., \& Simpson, P. J. (2002). The stereoscopic anisotropy affects manual pointing. Spatial Vision, 15, 443-458.

Braunstein, M. L. (1968). Motion and texture as sources of slant information. Journal of Experimental Psychology, 78, 247-253.

Bülthoff, H. H., \& Mallot, H. A. (1988). Integration of depth modules: Stereo and shading. Journal of the Optical Society of America A, 5, 1749-1758.

Ciuffreda, K. J., Wang, B., \& Vasudevan, B. (2007). Conceptual model of human blur perception. Vision Research, 47, 1245-1252.

Creem-Regehr, S. H., Gooch, A. A., Sahm, C. S., \& Thompson, W. B. (2004). Perceiving virtual geographic slant: Action influences perception. Journal of Experimental Psychology: Human Perception \& Performance, 30, 811-821.

Elliott, D., Whitaker, D., \& MacVeigh, D. (1990). Neural contribution to spatiotemporal contrast sensitivity decline in healthy ageing eyes. Vision Research, 30, 541-547.

Frisby, J. P., Buckley, D., \& Horsman, J. M. (1995). Integration of stereo, texture, and outline cues during pinhole viewing of real ridgeshaped objects and stereograms of ridges. Perception, 24, 181-198.

Gibson, J. J. (1950a). The perception of the visual world. Boston: Houghton Mifflin.

GiBson, J. J. (1950b). The perception of visual surfaces. American Journal of Psychology, 63, 367-384.

HABAK, C., \& FAUBERT, J. (2000). Larger effect of aging on the perception of higher-order stimuli. Vision Research, 40, 943-950.

Hall, G. S. (1922). Senescence: The last half of life. New York: Appleton.

Helmholtz, H. von (1925). Treatise on physiological optics (Vol. 3). Rochester, NY: Optical Society of America. (Original work published 1866)

Julesz, B. (1960). Binocular depth perception of computer-generated patterns. Bell System Technical Journal, 39, 1125-1162.

Julesz, B. (1964). Binocular depth perception without familiarity cues. Science, 145, 356-362.

Julesz, B. (1971). Foundations of cyclopean perception. Chicago: University of Chicago Press.

Kline, D. W., Schieber, F., Abusamra, L. C., \& Coyne, A. C. (1983). Age, the eye, and the visual channels: Contrast sensitivity and response speed. Journal of Gerontology, 38, 211-216.

Koenderink, J. J. (1986). Optic flow. Vision Research, 26, 161-180.

Laframboise, S., De Guise, D., \& Faubert, J. (2006). Effect of aging on stereoscopic interocular correlation. Optometry \& Vision Science, 83, 589-593.

Lappin, J. S., Shelton, A. L., \& Rieser, J. J. (2006). Environmental context influences visually perceived distance. Perception \& Psychophysics, 68, 571-581.

Loomis, J. M., Da Silva, J. A., Fujita, N., \& Fukusima, S. S. (1992). Visual space perception and visually directed action. Journal of Experimental Psychology: Human Perception \& Performance, 18, 906-921. 
Loomis, J. M., \& PhiLbeck, J. W. (1999). Is the anisotropy of perceived 3-D shape invariant across scale? Perception \& Psychophysics, 61, 397-402.

McGrath, C., \& Morrison, J. D. (1981). The effects of age on spatial frequency perception in human subjects. Quarterly Journal of Experimental Physiology, 66, 253-261.

Morrison, J. D., \& Reilly, J. (1986). An assessment of decision-making as a possible factor in the age-related loss of contrast sensitivity. Perception, 15, 541-552.

Newell, K. M., Vaillancourt, D. E., \& Sosnoff, J. J. (2006). Aging, complexity, and motor performance. In J. E. Birren \& K. W. Schaie (Eds.), Handbook of the psychology of aging (pp. 163-182). New York: Academic Press.

Newman, C. V., Whinham, E. A., \& MacRae, A. W. (1973). The influence of texture on judgments of slant and relative distance in a picture with suggested depth. Perception \& Psychophysics, 14, 280-284.

Norman, J. F., Clayton, A. M., Shular, C. F., \& Thompson, S. R. (2004). Aging and the perception of depth and 3-D shape from motion parallax. Psychology \& Aging, 19, 506-514.

Norman, J. F., Crabtree, C. E., Clayton, A. M., \& Norman, H. F. (2005). The perception of distances and spatial relationships in natural outdoor environments. Perception, 34, 1315-1324.

Norman, J. F., Crabtree, C. E., Herrmann, M., Thompson, S. R., Shular, C. F., \& Clayton, A. M. (2006). Aging and the perception of 3-D shape from dynamic patterns of binocular disparity. Perception \& Psychophysics, 68, 94-101.

Norman, J. F., Crabtree, C. E., Norman, H. F., Moncrief, B. K., Herrmann, M., \& Kapley, N. (2006). Aging and the visual, haptic, and cross-modal perception of natural object shape. Perception, 35, 1383-1395.

Norman, J. F., Dawson, T. E., \& Butler, A. K. (2000). The effects of age upon the perception of depth and 3-D shape from differential motion and binocular disparity. Perception, 29, 1335-1359.

Norman, J. F., Lappin, J. S., \& Norman, H. F. (2000). The perception of length on curved and flat surfaces. Perception \& Psychophysics, 62, 1133-1145.

Norman, J. F., Norman, H. F., Craft, A. E., Walton, C. L., BarthoLomew, A. N., Burton, C. L., ET AL. (2008). Stereopsis and aging. Vision Research, 48, 2456-2465.

Norman, J. F., Ross, H. E., Hawkes, L. M., \& Long, J. R. (2003). Aging and the perception of speed. Perception, 32, 85-96.

Norman, J. F., Todd, J. T., Perotti, V. J., \& Tittle, J. S. (1996). The visual perception of three-dimensional length. Journal of Experimental Psychology: Human Perception \& Performance, 22, 173-186.

Norman, J. F., Todd, J. T., \& Phillips, F. (1995). The perception of surface orientation from multiple sources of optical information. Perception \& Psychophysics, 57, 629-636.

Norman, J. F., \& Wiesemann, E. Y. (2007). Aging and the perception of local surface orientation from optical patterns of shading and specular highlights. Perception \& Psychophysics, 69, 23-31.

Ono, H., \& WAdE, N. J. (2005). Depth and motion in historical descriptions of motion parallax. Perception, 34, 1263-1273.

Owsley, C., Sekuler, R., \& Siemsen, D. (1983). Contrast sensitivity throughout adulthood. Vision Research, 23, 689-699.

Rieser, J. J., Ashmead, D. H., Talor, C. R., \& Youngquist, G. A. (1990). Visual perception and the guidance of locomotion without vision to previously seen targets. Perception, 19, 675-689.

Riggs, L. A. (1965). Visual acuity. In C. H. Graham, N. R. Bartlett, J. L. Brown, Y. Hsia, C. J. Mueller, \& L. A. Riggs (Eds.), Vision and visual perception (pp. 321-349). New York: Wiley.
Rogers, B., \& Graham, M. (1979). Motion parallax as an independent cue for depth perception. Perception, 8, 125-134.

Rogers, B., \& Graham, M. (1982). Similarities between motion parallax and stereopsis in human depth perception. Vision Research, 22, 261-270.

Rosas, P., Wichmann, F. A., \& Wagemans, J. (2004). Some observations on the effects of slant and texture type on slant-from-texture. Vision Research, 44, 1511-1535.

SAUnders, J. A. (2003). The effect of texture relief on perception of slant from texture. Perception, 32, 211-233.

Sekuler, R., \& Owsley, C. (1982). The spatial vision of older humans. In R. Sekuler, D. Kline, \& K. Dismukes (Eds.), Aging and human visual function (pp. 185-202). New York: Liss.

Snowden, R. J., \& Kavanagh, E. (2006). Motion perception in the ageing visual system: Minimum motion, motion coherence, and speed discrimination thresholds. Perception, 35, 9-24.

Steenhuis, R. E., \& Goodale, M. A. (1988). The effects of time and distance on accuracy of target-directed locomotion: Does an accurate short-term memory for spatial location exist? Journal of Motor Behavior, 20, 399-415.

Stevens, K. (1983). Slant-tilt: The visual encoding of surface orientation. Biological Cybernetics, 46, 183-195.

Stevens, S. S. (1975). Psychophysics: Introduction to its perceptual, neural, and social prospects. New York: Wiley.

Thomson, J. A. (1983). Is continuous visual monitoring necessary in visually guided locomotion? Journal of Experimental Psychology: Human Perception \& Performance, 9, 427-443.

ToDD, J. T. (1985). Perception of structure from motion: Is projective correspondence of moving elements a necessary condition? Journal of Experimental Psychology: Human Perception \& Performance, 11, 689-710.

TodD, J. T., \& AKerstrom, R. A. (1987). Perception of three-dimensional form from patterns of optical texture. Journal of Experimental Psychology: Human Perception \& Performance, 13, 242-255.

Todd, J. T., Norman, J. F., Koenderink, J. J., \& Kappers, A. M. L. (1997). Effects of texture, illumination, and surface reflectance on stereoscopic shape perception. Perception, 26, 807-822.

TodD, J. T., \& ReICHEL, F. D. (1989). Ordinal structure in the visual perception and cognition of smoothly curved surfaces. Psychological Review, 96, 643-657.

Todd, J. T., Thaler, L., \& Dijkstra, T. M. H. (2005). The effects of field of view on the perception of 3D slant from texture. Vision Research, 45, 1501-1517.

van Ee, R. (2001). Perceptual learning without feedback and the stability of stereoscopic slant estimation. Perception, 30, 95-114.

Watt, S. J., Akeley, K., Ernst, M. O., \& Banks, M. S. (2005). Focus cues affect perceived depth. Journal of Vision, 5, 834-862.

WeAle, R. A. (1963). The aging eye. New York: Lewis.

Wheatstone, C. (1838). Contributions to the physiology of vision: Part the first. On some remarkable, and hitherto unobserved, phenomena of binocular vision. Philosophical Transactions of the Royal Society of London, 128, 371-394.

Zimmerman, G. L., Legge, G. E., \& Cavanagh, P. (1995). Pictorial depth cues: A new slant. Journal of the Optical Society of America A, 12, 17-26.

(Manuscript received May 7, 2007; revision accepted for publication July 5, 2008.) 